\title{
MojGozdar.si zagotavlja sistem potrebne skrbnosti in sledljivosti gozdnih lesnih sortimentov
}

Jaša Saražin, Gozdarski inštitut Slovenije, Oddelek za gozdno tehniko in ekonomiko Matevž Triplat, Gozdarski inštitut Slovenije, Oddelek za gozdno tehniko in ekonomiko

Objavljeno na spletu 31.01.2022 (https://doi.org/10.20315/IG.2022.0010) 


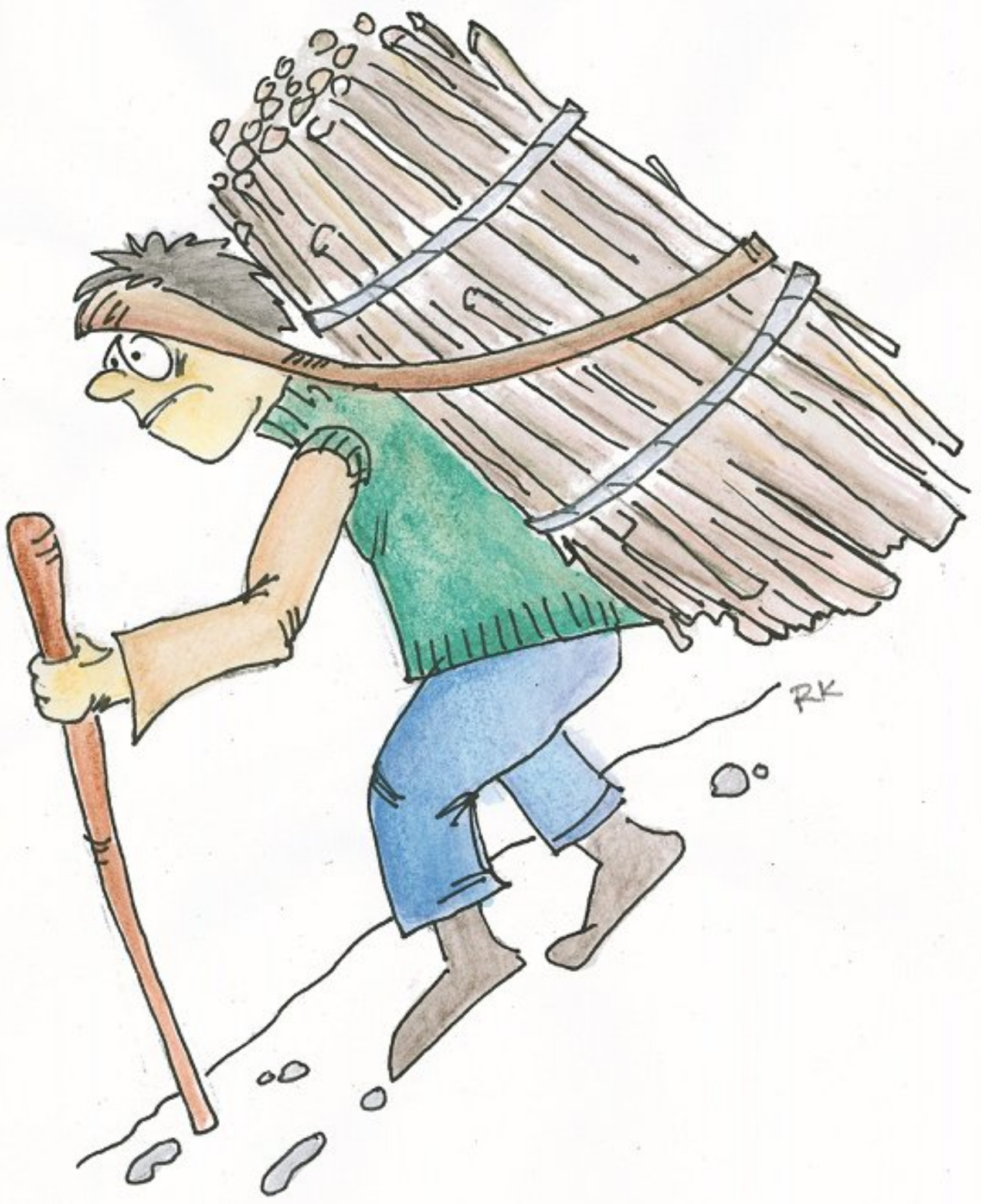

Spletni sistem MojGozdar.si je že od leta 2017 pomemben povezovalni člen med slovenskimi lastniki gozdov in ostalimi iskalci gozdarskih storitev na eni strani ter ponudniki gozdarskih storitev na drugi 
strani. Uporabnikom omogoča širok nabor možnosti od iskanja izvajalcev ter navezavi stika z njimi, do digitalnega vodenja ključne dokumentacije povezane z izvedbo gozdarskih del (Triplat in sod., 2018; Vodnik, 2019). V sklopu projekta eGozd, s partnerji izvajamo testiranje naprednejših orodij spletnega sistema ter izvajamo njegove popravke in nadgradnje, da bo lahko v prihodnje še bolje služil vsem akterjem, ki so povezani z izvedbo del v slovenskih zasebnih gozdovih.

\section{Prvi sklop delavnic projekta eGozd - sistem potrebne skrbnosti in sledljivosti z gozdnimi lesnimi sortimenti}

Prva spletna delavnica projekta eGozd je bila namenjena urejanju digitalnih evidenc projektnih partnerjev, ki služijo zagotavljanju sistema potrebne skrbnosti in sledljivosti z gozdnimi lesnimi sortimenti, ki ga določa Uredba EU o lesu (2010).

Z namenom zaščite svetovnih gozdnih virov, ublažitve podnebnih spremembe in zaščite biotske raznovrstnosti je mednarodna skupnost oblikovala politične ukrepe za spodbujanje trajnostnega gospodarjenja z gozdovi ter boj proti nezakoniti sečnji in z njo povezani trgovini. Nezakonita sečnja povzroča škodo $v$ gozdih, kar vpliva na podnebje, biotsko raznovrstnost in gospodarstvo. Eden od vzrokov je mednarodna trgovina, ki jo poganja povpraševanje potrošniških držav. Leta 2003 je EU sprejela akcijski načrt Forest Law Enforcement, Governance and Trade (FLEGT), ki velja za osrednji dokument in predvideva različne ukrepe za preprečevanje uvoza nezakonitega lesa. Med njimi je tudi izvajanje evropske uredbe o lesu (EUTR, 2010) in izvajanje prostovoljnih sporazumov o partnerstvu. EUTR (2010) od leta 2013 prepoveduje dajanje lesa in lesnih proizvodov iz nezakonitih virov na evropski trg. Nezakonit les je opredeljen kot les pridobljen $v$ nasprotju z zakonodajo veljavno $v$ državi pridobivanja. EUTR (2010) od pravnih in fizičnih oseb zahteva, da v primeru, ko prvič dajejo les ali lesne proizvode na evropski trg ravnajo s potrebno skrbnostjo in s tem povezano sledljivostjo lesa in lesnih proizvodov. Skladno z uredbo je potrebno za zadnjih 5 let zagotavljati informacije o:

- vrsti proizvoda,

- drevesni vrsti in količini lesa,

- dovoljenju za posek,

- imenu in naslovu prejemnika oz. trgovca, kateremu je dobavil oz. prodal gozdne lesne sortimente, ter morebitna druga dovoljenja.

Bistvo "sistema potrebne skrbnosti" je, da gospodarski subjekti izvajajo ukrepe za obvladovanje tveganja, da bi čim bolj zmanjšali tveganje dajanja nezakonito pridobljenega lesa ali lesnih proizvodov, ki vsebujejo nezakonito pridobljen les, na trg. V EUTR (2010) ima na primer sistem potrebne skrbnosti tri ključne elemente zbiranje informacij, ocenjevanje tveganj in zmanjševanje tveganj. Če tveganje ni zanemarljivo, je treba navesti tudi ukrepe za zmanjšanje tveganja.

Osnova za zagotavljanje sistema potrebne skrbnosti in sledljivosti z gozdnimi lesnimi sortimenti, je posedovanje dovoljenja za posek (običajno je to odločba izdana s strani ZGS) in pogodbe z izvajalcem gozdarskih storitev, medtem ko lahko vse ostale potrebne listine uredimo preko spletnega sistema MojGozdar.si.

Za urejanje digitalnih evidenc zadostuje brezplačna registracija in prijava v sistem. Za tem pa nas sistem z vprašanji vodi preko listin, ki jih v dotičnem primeru potrebujemo: ali naj bo to evidenčni list, knjigovodska listina, ali izjava o prevozu. Za lažje urejanje digitalnih evidenc na Mojgozdar.si je bil 
pripravljen tudi video vodnik, ki je dostopen na naslednji povezavi:

https://www.youtube.com/watch?v=INbgJ2kjr7l (Triplat, 2018).

Moj Gozdar

Izvajalci O nas Vodnik Novice Novo povpraševanje

Jaša Saražin .

\section{Digitalne evidence 彎}

Odjava

Urejanje profila

Digitalne evidence

Pogodbe (1)

Ponudbe in povpraševanja

Prikaži $10 \quad v$ zadetkov na stran

\begin{tabular}{|c|c|c|c|c|c|c|c|c|c|}
\hline $\begin{array}{l}\text { Zap. } \\
\text { št. }\end{array}$ & $\begin{array}{l}\text { Št. } \\
\text { odločbe }\end{array}$ & $\begin{array}{l}\text { Evidenčni } \\
\text { list }\end{array}$ & $\begin{array}{l}\text { Datum } \\
\text { odprodaje }\end{array}$ & Prejemnik & $\begin{array}{l}\text { Drevesna } \\
\text { vrsta }\end{array}$ & $\begin{array}{l}\text { Gozdni lesni } \\
\text { sortimenti }\end{array}$ & Količina & SKUPAJ & $\begin{array}{l}\text { Knjigovodska listina / Izjava o } \\
\text { prevozu }\end{array}$ \\
\hline 1 & od & 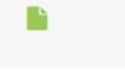 & 10. 08.2021 & $\begin{array}{l}\text { Lastna } \\
\text { uporaba }\end{array}$ & $\begin{array}{l}\text { Smreka } \\
\text { Bukev }\end{array}$ & $\begin{array}{l}\text { 1. Hlodi } \\
\text { 4.1 Goli za drva }\end{array}$ & $\begin{array}{l}180,00 \mathrm{~m} 3 \\
22,50 \mathrm{~m} 3\end{array}$ & $\begin{array}{l}217,30 \mathrm{~m} 3 \\
20,00 \mathrm{prm}\end{array}$ & E \\
\hline
\end{tabular}

Slika: Modul za pripravo in vodenje digitalnih evidenc (vodenje potrebne skrbnosti in sledljivosti z gozdnimi lesnimi sortimenti) v spletnem sistemu MojGozdar.si

Skupaj s kmetijskimi gospodarstvi, ki so na skupnih in individualnih delavnicah urejali svoje digitalne evidence, smo izdelali predlog izboljšav, ki bodo po njihovi implementaciji, zagotovile boljšo uporabniško izkušnjo.

\section{Prihajajoče novosti na spletnem sistemu MojGozdar.si}

Sedaj smo v obdobju intenzivnih nadgradenj spletnega sistema, ki bodo poleg izboljšav modula za urejanje digitalnih evidenc, bistveno izboljšale tudi modul za oddajo skupinskega povpraševanja ter postavile nov modul za izdelavo načrta za gozdno posest.

\section{Zahvala}

Projektu »eGozd - Elektronsko poslovanje kmetijskih gospodarstev z izrazito gozdarsko dejavnostjo«, katerega vodilni partner je Gozdarski inštitut Slovenije. Projekt je prejel odobrena sredstva financiranja v višini 347.222,86 EUR in se v celoti financira iz razpisa M16.2. Začel se je s 1. 8. 2020 in bo potekal 36 mesecev (oz. do 31. 7. 2023). Partnerji v projektu so Zavod za gozdove Slovenije, Razvojni center koroškega gospodarstva d. o. o., Arctur d. o. o., Zveza lastnikov gozdov Slovenije, Jure Čas - Kmetija Čas, Sara Berglez Zajec - Kmetija Lipnik, Srečko Bricman - Kmetija Temnikar, Leopold Pustinek - Kmetija Sp. Pustinek, Marjana Vošner - Kmetija Metniger, Agrarna skupnost Čezsoča, Darko Prezelj - Kmetija Pr' Šoštarju in Janez Benedičič - Kmetija Pr' Demšari. 

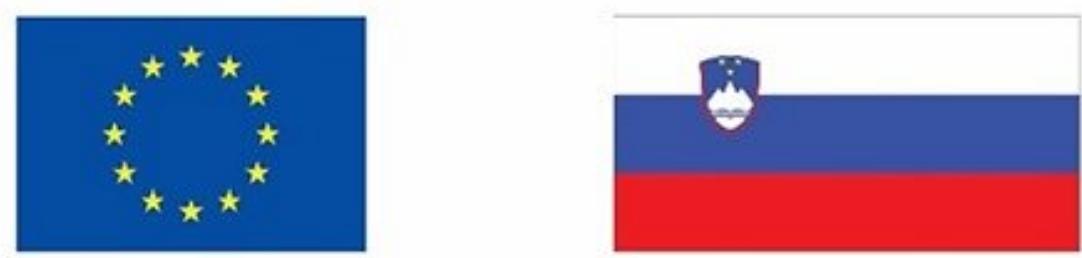

\section{Evropski kmetijski sklad za razvoj podeželja: Evropa investira v podeželje}

Viri

- Triplat M., Piškur M., Krajnc N. 2018. Spletni informacijski sistem MojGozdar.si. GozdVestn 76 (3): 141-151

- Vodnik, MojGozdar. GIS. (dostop 19.1.2022) https://www.mojgozdar.si/vodnik/

- Triplat M. Vodnik - digitalne evidence, MojGozdar. GIS. (dostop 19.1.2022) https://www.youtube.com/watch?v=|NbgJ2kjr7I

- Uredba EU o lesu. 2010. Uredba EU št. 995/2010 Evropskega parlamenta in sveta 